Article

\title{
Long-Term Combined Effects of Citrulline and Nitrate-Rich Beetroot Extract Supplementation on Recovery Status in Trained Male Triathletes: A Randomized, Double-Blind, Placebo-Controlled Trial
}

\author{
José Burgos ${ }^{1,2}$, Aitor Viribay ${ }^{3}$, Julio Calleja-González ${ }^{4} \mathbb{D}$, Diego Fernández-Lázaro ${ }^{5,6} \mathbb{D D}^{\mathbb{D}}$, \\ Jurgi Olasagasti-Ibargoien ${ }^{7,8} \mathbb{D}$, Jesús Seco-Calvo ${ }^{9,+} \mathbb{D}$ and Juan Mielgo-Ayuso ${ }^{10, *(\mathbb{D}}$
}

check for

updates

Citation: Burgos, J.; Viribay, A.;

Calleja-González, J.; Fernández-

Lázaro, D.; Olasagasti-Ibargoien, J. Seco-Calvo, J.; Mielgo-Ayuso, J. Long-Term Combined Effects of Citrulline and Nitrate-Rich Beetroot

Extract Supplementation on Recovery Status in Trained Male Triathletes: A Randomized, Double-Blind, Placebo-Controlled Trial. Biology 2022, 11, 75. https://doi.org/ 10.3390/biology11010075

Academic Editors: Filipe Manuel Clemente, Georgian Badicu, Eugenia Murawska-Ciałowicz and Carlo Reggiani

Received: 30 November 2021 Accepted: 31 December 2021 Published: 4 January 2022

Publisher's Note: MDPI stays neutral with regard to jurisdictional claims in published maps and institutional affiliations.

Copyright: (C) 2022 by the authors. Licensee MDPI, Basel, Switzerland. This article is an open access article distributed under the terms and conditions of the Creative Commons Attribution (CC BY) license (https:// creativecommons.org/licenses/by/ $4.0 /)$
1 Department of Nursing and Physiotherapy, University of León, 24071 León, Spain; joseburgos88@hotmail.com 2 Burgos Nutrition, Physiology, Nutrition and Sport, 26007 Logroño, Spain

3 Glut4Science, Physiology, Nutrition and Sport, 01004 Vitoria-Gasteiz, Spain; aitor@glut4science.com

4 Department of Physical Education and Sport, Faculty of Education and Sport, University of the Basque Country, 01007 Vitoria-Gasteiz, Spain; julio.calleja.gonzalez@gmail.com

5 Department of Cellular Biology, Histology and Pharmacology, Faculty of Health Sciences, University of Valladolid, 42003 Soria, Spain; diego.fernandez.lazaro@uva.es

6 Neurobiology Research Group, Faculty of Medicine, University of Valladolid, 47005 Valladolid, Spain

7 Faculty of Education and Sports, University of Deusto, 20012 Donostia-San Sebastian, Spain; jurgi.olasagasti@deusto.es

8 Health, Physical Activity and Sports Science Laboratory (HealthPASS), Departament of Physical Activity and Sport, Faculty of Education and Sport, University of Deusto, 48007 Bilbao, Spain

9 Physiotherapy Department, Institute of Biomedicine (IBIOMED), University of Leon, Campus de Vegazana, 24071 Leon, Spain; dr.seco.jesus@gmail.com

10 Department of Health Sciences, Faculty of Health Sciences, University of Burgos, 09001 Burgos, Spain

* Correspondence: jfmielgo@ubu.es

+ Researcher of Basque Country University.

Simple Summary: Recovery is one of the main elements in achieving adequate athletic performance. Various supplements have been used for this purpose. Citrulline (CIT) and Nitrate-Rich Beetroot Extract (BR) are so-called nitric oxide precursor supplements that have shown an ergogenic effect on sports performance when used on a short-term, individual basis. These supplements appear to have other pathways that may promote athletic performance. The purpose of this study was to assess the effect of a co-supplementation for 9 weeks of $3 \mathrm{~g} /$ day of CIT plus $2.1 \mathrm{~g} /$ day of BR (300 mg/day of nitrates) on recovery by exercise-induced muscle damage markers (EIMD), anabolic/catabolic hormones and distance covered in the Cooper test (CP). Thirty-two male triathletes were randomized into 4 groups of 8 in this double-blind, placebo-controlled trial: placebo group, CIT group, BR group and CIT-BR group. Blood samples and CP were collected at baseline and after 9 weeks. The main conclusions were the combination of $3 \mathrm{~g} /$ day of CIT plus $2.1 \mathrm{~g} /$ day of BR $\left(300 \mathrm{mg} /\right.$ day of $\left.\mathrm{NO}_{3}{ }^{-}\right)$ supplementation for 9 weeks did not present any benefit for EIMD. However, CIT-BR improved recovery status by preventing an increase in cortisol and showing an increase in Testosterone/Cortisol ratio and distance covered in the $\mathrm{CP}$.

\begin{abstract}
Citrulline (CIT) and nitrate-rich beetroot extract (BR) are widely studied ergogenic aids Nevertheless, both supplements have been studied in short-term trials and separately. To the best of the authors' knowledge, the effects of combining CIT and BR supplementation on recovery status observed by distance covered in the Cooper test, exercise-induced muscle damage (EIMD) and anabolic/catabolic hormone status have not been investigated to date. Therefore, the main purpose of this research was to assess the effect of the long-term (9 weeks) mixture of $3 \mathrm{~g} /$ day of CIT plus $2.1 \mathrm{~g} /$ day of BR (300 mg/day of nitrates $\left.\left(\mathrm{NO}_{3}{ }^{-}\right)\right)$supplementation on recovery by distance covered in the Cooper test, EIMD markers (urea, creatinine, AST, ALT, GGT, LDH and $\mathrm{CK}$ ) and anabolic/catabolic hormones (testosterone, cortisol and testosterone/cortisol ratio (T/C)) in male trained triathletes. Thirty-two triathletes were randomized into four different groups of
\end{abstract}


eight triathletes in this double-blind, placebo-controlled trial: placebo group (PLG), CIT group (CITG; $3 \mathrm{~g} /$ day of CIT), BR group (BRG; $2.1 \mathrm{~g} /$ day of BR (300 mg/day of $\left.\mathrm{NO}_{3}{ }^{-}\right)$) and CIT-BR group (CIT-BRG; $3 \mathrm{~g} /$ day of CIT plus $2.1 \mathrm{~g} /$ day of BR $\left(300 \mathrm{mg} /\right.$ day of $\left.\left.\mathrm{NO}_{3}{ }^{-}\right)\right)$. Distance covered in the Cooper test and blood samples were collected from all participants at baseline (T1) and after 9 weeks of supplementation (T2). There were no significant differences in the interaction between group and time in EIMD markers (urea, creatinine, AST, ALT, GGT, LDH and CK) ( $p>0.05)$. However, significant differences were observed in the group-by-time interaction in distance covered in the Cooper test $\left(p=0.002 ; \eta^{2} p=0.418\right)$, cortisol $\left(p=0.044 ; \eta^{2} p=0.247\right)$ and T/C $\left(p=0.005 ; \eta^{2} p=0.359\right)$. Concretely, significant differences were observed in distance covered in the Cooper test percentage of change ( $p=0.002 ; \eta^{2} p=0.418$ ) between CIT-BRG and PLG and CITG, in cortisol percentage change $\left(p=0.049 ; \eta^{2} p=0.257\right)$ and in T/C percentage change $\left(p=0.018 ; \eta^{2} p=0.297\right)$ between CIT-BRG and PLG. In conclusion, the combination of $3 \mathrm{~g} /$ day of CIT plus $2.1 \mathrm{~g} /$ day of BR $\left(300 \mathrm{mg} /\right.$ day of $\left.\mathrm{NO}_{3}{ }^{-}\right)$ supplementation for 9 weeks did not present any benefit for EIMD. However, CIT + BR improved recovery status by preventing an increase in cortisol and showing an increase in distance covered in the Cooper test and $\mathrm{T} / \mathrm{C}$.

Keywords: triathlon; performance; ergogenic aids; muscle fatigue; recovery; hormones

\section{Introduction}

Prolonged and strenuous exercise produces organic stress [1] that could decrease athletic performance [2-4]. As a consequence of this status, there are several alterations in biochemical parameters of exercise-induced muscle damage (EIMD) [5] as well as anabolic/catabolic hormone alterations which could hinder endogenous exercise adaptations [6]. Therefore, in addition to an adequate training program, it could be essential to include different strategies to delay or reduce muscle fatigue and improve adaptation to training [7]. In this sense, supplementation with nitrate-rich beetroot extract (BR) and citrulline (CIT) has been proposed to achieve these goals, partly because they are precursors of nitric oxide (NO) [8-11].

The NO produces vasodilation by increasing the blood level in muscles and improving their efficiency in muscle contraction and relaxation processes [12]. Moreover, NO regulates force generation and satellite cell activation [13]. In the long term, NO can regulate muscle function and even affect skeletal muscle recovery due to its antioxidant effect and the constant increase in muscle blood flow which, together with an adequate supply of essential amino acids, would allow better muscle fueling [14] and could prevent EIMD [15,16]. Moreover, decreased blood flow to the testis could reduce testosterone synthesis [17]. It has also been shown in animal models that $\mathrm{NO}$ enhancement resulted in a significant reduction of ACTH-mediated cortisol production [18]. Consequently, although this mechanism is speculative, increasing NO could improve blood flow in the testis and promote testosterone synthesis by vasodilator effect $[14,19]$ and could be successful in maintaining an anabolic state, decreasing muscular damage and metabolic stress [2,9].

On the one hand, BR supplementation is widely used by athletes as a precursor of $\mathrm{NO}$ [20]. When the athletes digest $\mathrm{BR}$, its nitrates $\left(\mathrm{NO}_{3}{ }^{-}\right)$are transformed into nitrites $\left(\mathrm{NO}_{2}{ }^{-}\right)$which are partially reduced to $\mathrm{NO}$ by the action of stomach acids and subsequently absorbed in the intestine and passed into the bloodstream [21]. Moreover, BR is rich in other compounds such as phenolic acids, flavonoids, carotenoids and betalains, which have antioxidant effects [22]. Therefore, although the mechanisms for potential improvements in muscle recovery following EIMD after $\mathrm{NO}_{3}{ }^{-}$supplementation are not clear, it would be expected that long-term BR supplementation could attenuate EIMD after prolonged, strenuous exercise $[22,23]$ based on the effects of $\mathrm{NO}$ and additional compounds. Moreover, long-term BR supplementation could be very beneficial for the maintenance of anabolic/catabolic hormones, as shown by Sarfaraz et al. on testosterone levels [24]. However, short-term BR supplementation (maximum for 3 days) has not presented an improved 
EIMD and anabolic/catabolic status after a damaging session of eccentric exercise [23] or high-intensity workouts [25], which opens the need for further research.

On the other hand, citrulline (CIT), a non-essential amino acid found primarily in watermelon and produced endogenously by recycling into arginine (ARG) and NO via argininosuccinate synthetase, increases NO availability and its effects [26]. In addition, CIT is an essential element of the urea cycle in the liver [27]. Therefore, it has been suggested that CIT supplementation may eliminate ammonia by urea production [28]. In the same way, CIT is an important activator of muscle protein synthesis in catabolic situations via activation of the mammalian target of rapamycin (mTOR) pathway due to its key role in the regulation of nitrogen homeostasis [29]. Based on these mechanisms, CIT supplementation may favor muscle performance and recovery in different ways, such as activating muscle protein synthesis, improving oxygen distribution to muscle, increasing oxidative ATP production during exercise and phosphocreatine $(\mathrm{PCr})$ during exercise recovery and decreasing blood lactate and ammonium production [14,30,31], which could reduce fatigue and limit EIMD. However, although this proposal would be adequate for athletes, to the best of the authors' knowledge, there is little research on CIT supplementation in muscle recovery. In this regard, Da Silva et al. [27] did not observe improvements in functional (i.e., number of maximum repetitions, muscle pain and perceived effort), metabolic (i.e., $\mathrm{CK}$ and lactate), anabolic (i.e., testosterone and testosterone/cortisol (T/C) ratio) and physiological (electromyographic signal) outcomes of muscle recovery in untrained young adult males after CIT supplementation with $6 \mathrm{~g}$ at $60 \mathrm{~min}$ prior to the training session. These results of both CIT and BR supplementation on EIMD and anabolic/catabolic hormones may probably be due to the fact that the effects have only been investigated in the short term [28] and under isolated intakes [29,32], suggesting the need to investigate the effects of long-term combination of these two ergogenic aids. In this regard, it has been shown that the effects of some supplements can be synergic when combined over the long term $[2,33]$. Therefore, it could be considered that the combined effects of CIT (NO precursor and activator of muscle protein synthesis) and BR (NO precursor and antioxidant effect) could reduce EIMD and improve muscle recovery observed by anabolic/catabolic hormone profile $[34,35]$. This could favor some sporting performance variables [36]. In this sense, the supplementation of $6 \mathrm{~g}$ of CIT plus $520 \mathrm{mg}$ of $\mathrm{NO}_{3}{ }^{-} 6 \mathrm{~h}$ before the submaximal incremental cycling test has shown improvements in some cardiorespiratory variables, such as $\mathrm{VO}_{2}$ [36].

Therefore, the main objective of this research was to assess the effect of the long-term (9 weeks) mixture of $3 \mathrm{~g} /$ day of CIT plus $2.1 \mathrm{~g} /$ day of $\mathrm{BR}\left(300 \mathrm{mg} /\right.$ day of $\mathrm{NO}_{3}{ }^{-}$) supplementation on recovery status, distance covered in the Cooper test, EIMD markers (urea, creatinine, AST, ALT, GGT, LDH and CK) and anabolic/catabolic hormones (testosterone, cortisol and $\mathrm{T} / \mathrm{C}$ ) in male trained triathletes. The hypothesis was that the combination of CIT plus BR could limit EIMD and improve endogenous recovery observed in lower cortisol and better testosterone and T/C than isolated CIT or BR supplementation.

\section{Materials and Methods}

\subsection{Participants}

Thirty-two male amateur triathletes from the same club $(34.37 \pm 7.08$ years old and $58.79 \pm 6.89 \mathrm{~mL} / \mathrm{min} / \mathrm{kg}$ of $\mathrm{VO}_{2 \max }$ ) with at least 5 years of experience participated in this trial. All athletes rigorously performed the same training methodology, and thus, all of them were exposed to the same training load in terms of type, intensity and duration of exercise (Table 1): $15 \mathrm{~h} /$ week, 6 days/week during the 9 weeks. All participants completed a total of $135 \mathrm{~h}$ of training during the study. 
Table 1. Type, intensity and duration of weekly training program.

\begin{tabular}{|c|c|c|c|c|c|c|c|}
\hline & Monday & Tuesday & Wednesday & Thursday & Friday & Saturday & Sunday \\
\hline $\begin{array}{c}\text { 1st } \\
\text { session }\end{array}$ & $\begin{array}{l}-20 \text { warm-up } \\
\text { - } 15 \text { min } \\
\text { stretching } \\
-45 \text { min } \\
\text { mindfulness }\end{array}$ & $\begin{array}{l}\text { - } 15 \text { min run } \\
\text { technique skills } \\
\text { - } 45 \text { min strength } \\
\text { training }\end{array}$ & $\begin{array}{l}\text { - } 120 \mathrm{~m} \text { ride at } \\
50-75 \% \\
\mathrm{VO}_{2 \mathrm{max}} \\
-15 \text { min } \\
\text { cooldown } \\
\text { - } 15 \text { min core }\end{array}$ & $\begin{array}{l}\text { - } 15 \text { min run } \\
\text { technique skills } \\
\text { - } 45 \text { min strength } \\
\text { training }\end{array}$ & $\begin{array}{l}-75 \text { min run at } \\
50-75 \% \\
\mathrm{VO}_{2 \mathrm{max}} \\
\text { - } 20 \text { min } \\
\text { resistance } \\
\text { training }\end{array}$ & $\begin{array}{l}-75 \text { min swim at } \\
\quad 75-90 \% \mathrm{VO}_{2 \max }\end{array}$ & $\begin{array}{l}\text { - } 15 \text { min run } \\
\text { technique } \\
\text { skills } \\
\text { - } 45 \text { min } \\
\text { strength } \\
\text { training }\end{array}$ \\
\hline $\begin{array}{c}\text { 2nd } \\
\text { session }\end{array}$ & REST & $\begin{array}{l}-30 \text { min } \\
\text { warm-up } \\
-30 \text { min run at } \\
75-90 \% \mathrm{VO}_{2 \max } \\
\text { - } 15 \text { min } \\
\text { cooldown }\end{array}$ & REST & $\begin{array}{l}\text { - } 30 \text { min } \\
\text { warm-up } \\
\text { - } 30 \text { min swim at } \\
75-90 \% \mathrm{VO}_{2 \max } \\
\text { - } 15 \text { min } \\
\text { cooldown }\end{array}$ & REST & - 60 min walk & $\begin{array}{l}-120 \text { min ride } \\
\text { at } 50-75 \% \\
\mathrm{VO}_{2 \max } \\
\text { - } 15 \text { min core }\end{array}$ \\
\hline
\end{tabular}

Likewise, a certified nutritionist (CLR-0020) developed personalized diets for each participant. These diets were planned with the aim of ensuring adequate energy and macro and micronutrient intake considering the training load and the personal features of each triathlete following the international recommendations for an adequate sports performance [37].

All athletes also underwent a medical examination and completed a medical history questionnaire prior to the start of the study to find out whether they had any type of disease and/or injury [38]. The participants did not present any disease, and they did not drink alcohol, smoke or consume other drugs or stimulant substances during the study period which could alter the hormone response. Likewise, to eliminate the probable interference of other nutritional aids with the different outcomes measured in this research, a 2-week washout period was included [39-41].

All triathletes were completely informed of all actions of the study and signed a personal statement of informed consent, giving their individual agreement to take part in the proposed work. This trial was considered in accordance with the Declaration of Helsinki (2008) and the Fortaleza update (2013) and was approved by the Human Research Ethics Committee of the University of León, Spain (number: ULE-020-2020). Moreover, this study was registered in clinicaltrials.gov with NCT05143879 number.

\subsection{Experimental Protocol and Evaluation Plan}

This study was planned as a randomized, double-blind, placebo-controlled trial to assess the impact of a 9-week oral supplementation of the combination of CIT plus BR on recovery status by distance-covered performance test, EIMD markers and anabolic/catabolic hormones in this sport population. The proposed doses of CIT ( $3 \mathrm{~g} /$ day) and BR supplements were based on previous scientific studies that found favorable results with similar doses [42-44].

The 32 athletes were randomly assigned to four different groups of 8 participants (Table 2) by an independent statistician using the open-source software OxMaR (Oxford Minimization and Randomization, 2014): (I) placebo group (PLG); (II) CIT group (CITG); (III): nitrate-rich beetroot extract group (BRG); and (IV) CIT-BR group (CIT-BRG).

Table 2. Age and height of participants at the beginning of the study.

\begin{tabular}{lcccc}
\hline & PLG $(\boldsymbol{n}=\mathbf{8})$ & CITG $(\boldsymbol{n}=\mathbf{8})$ & BRG $(\boldsymbol{n}=\mathbf{8})$ & CIT-BRG $(\boldsymbol{n}=\mathbf{8})$ \\
\hline Age $($ years $)$ & $34.01 \pm 7.03$ & $32.75 \pm 7.01$ & $32.67 \pm 6.54$ & $34.35 \pm 7.95$ \\
\hline Height $(\mathrm{cm})$ & $179 \pm 8 \mathrm{~cm}$ & $180 \pm 9 \mathrm{~cm}$ & $178 \pm 8 \mathrm{~cm}$ & $181 \pm 6 \mathrm{~cm}$ \\
\hline Data are presented as mean \pm standard deviation.
\end{tabular}

CIT supplementation was included in 3 gelatin capsules of $1 \mathrm{~g}$ CIT by Hard Eight $\mathrm{Nu}-$ trition LLC (7511 Eastgate Rd, Henderson, NV 89011). BR supplementation was included 
in 3 gelatin capsules of $700 \mathrm{mg}$ ( $5: 1$ beetroot extract equivalent to $3500 \mathrm{mg}$ of whole dried root, standardized to contain $0.3 \%$ betanin providing $100 \mathrm{mg}$ of $\mathrm{NO}_{3}{ }^{-}$) by Lindens Health Nutrition (1 Calder Point, Monckton Road, Wakefield, WF2 7AL). The placebo (cellulose) capsules were made of both $1 \mathrm{~g}$ and $700 \mathrm{mg}$ being of the same color and shape as the other two supplements to avoid the placebo effect [45]. All athletes took the same number of capsules per day ( 3 capsules of $1 \mathrm{~g}$ (BIG) and 3 capsules of $700 \mathrm{mg}$ (SMALL)) based on their groups: PLG: 3 BIG of cellulose + 3 SMALL of cellulose; CIT: 3 BIG CIT and 3 SMALL of cellulose; BR: 3 BIG of cellulose + 3 SMALL BR; and CIT-BRG: 3 BIG CIT + 3 SMALL BR. In order to ensure blinding, all BIG capsules were white (CIT and placebo) and all SMALL capsules were red (BR and placebo).

All participants took 3 BIG and 3 SMALL capsules, either the placebo or aids, during the 7 days of the week after each of the 3 main meals (1-1-1) to eliminate any influence of circadian variation [46]. Athletes were informed that they should not brush their teeth or rinse their mouths for $2 \mathrm{~h}$ after the intake of the capsules, based on the effect of oral bacteria on the reduction of $\mathrm{NO}_{2}{ }^{-}$from $\mathrm{NO}_{3}{ }^{-}$. In addition, they were unaware of the contents of the capsules provided to them weekly by an independent nutritionist (LR003) who confirmed that all triathletes complied with the intake protocol.

\subsection{Blood Collection}

All triathletes arrived at the laboratory at 8:30 a.m. for blood extraction at two different moments during the trial: (T1) at baseline and (T2) after 9 weeks of supplementation. For the evaluation/assessment of EIMD and hormonal outcomes at T1 and T2, antecubital venous blood samples were collected. All samples were obtained after at least $12 \mathrm{~h}$ of fasting and $48 \mathrm{~h}$ without any previous exercise and after being at rest for $30 \mathrm{~min}$.

The EIMD markers (urea, creatinine, AST, ALT, GGT, CK and LDH) were measured using the Hitachi $917^{\circledR}$ automatic autoanalyzer (Hitachi Ltd., Tokyo, Japan) [47]. Serum hormone outcomes (total testosterone and cortisol) were measured using an enzyme-linked fluorescent assay with the aid of a multiparametric analyzer (MINI VIDAS ${ }^{\circledR}$, Biomerieux, Marcy l'Etoile, France) [3]. The substrate 4-methylumbelliferone was used, and fluorescence emission was performed at $450 \mathrm{~nm}$ and, after stimulation, at $370 \mathrm{~nm}$ [48]. The intra-assay $\mathrm{CV}$ was $5.7 \%$, and the $\mathrm{CV}$ of the intermediate assay was $6.2 \%$. Finally, $\mathrm{T} / \mathrm{C}$ was considered by dividing testosterone by cortisol.

\subsection{Cooper Test}

After blood analysis and $2 \mathrm{~h}$ after the standardized breakfast $(2 \mathrm{~g}$ of $\mathrm{CHO} / \mathrm{kg} \mathrm{BM}$ and consisting of rice, corn cereal with oat beverage, cooked fruit and biscuits with jam or sweet quince, cheese or paste) [37], the athletes performed a Cooper test. Athletes were familiar with this test given that they usually use this test throughout the season.

Before starting the test, a standardized $15 \mathrm{~min}$ warm-up was performed: $8 \mathrm{~min}$ incremental run; 3 min of core work; 2 min of trunk, hip and leg muscle exercises; and 2 min of different types of jumps. The Cooper 12 min run test was conducted under the observation of the research team on a $400 \mathrm{~m}$ synthetic sports track. The participants completed the traditional test protocol, which consisted of covering the farthest feasible distance in $12 \mathrm{~min}$ [49]. The total distance covered in this time was measured immediately after the test was completed using markers placed on the track at $50 \mathrm{~m}$ intervals [50].

\subsection{Anthropometry}

The same internationally certified anthropometrist (ISAK level 3 with certificate number: \#636739292503670742) performed the anthropometric measurements for all triathletes based on the International Society for the Advancement of Kinanthropometry (ISAK) protocol [51]. Height $(\mathrm{cm})$ was obtained by a SECA ${ }^{\circledR}$ measuring rod (Mod. 220; SECA Medical, Bradford, MA, USA), with $1 \mathrm{~mm}$ precision. Body mass $(\mathrm{kg})$ was measured using a SECA ${ }^{\circledR}$ model scale (Mod. 220; SECA Medical, Bradford, MA, USA), with $0.1 \mathrm{~kg}$ precision. Body mass index (BMI) was considered by the equation body mass $/$ height ${ }^{2}\left(\mathrm{~kg} / \mathrm{m}^{2}\right)$. Six skin- 
folds (mm) were assessed-triceps, subscapular, supraspinal, abdominal, front thigh and medial calf by a Harpenden ${ }^{\circledR}$ Skinfold Caliper (Harpenden Skinfold Caliber, British Indicators Ltd., London, UK) with $0.2 \mathrm{~mm}$ precision-and the sum of all of them was considered. Girths (cm) (relaxed arm, flexed arm, minimum waist, $1 \mathrm{~cm}$ below the buttock thigh, midthigh and calf girth) were measured with an inextensible metallic Lufkin ${ }^{\circledR}$ measuring tape model W606PM (Cooper Tools, Apex, NC, USA) with $1 \mathrm{~mm}$ precision. Fat mass (FM) and muscle mass (MM) were estimated by the Carter and Lee equations, respectively [52].

\subsection{Dietary Assessment}

The nutritionists participating in the study (J.B.-B. and J.M.-A.) informed all triathletes about proper food tracking. They tutored the participants regarding 2 validated methods of dietary recall [51]. The first method was a food frequency questionnaire (FFQ) previously used in other sport populations [53] which triathletes should complete at T2. The athletes should recall their average food "frequency" intake based on certain food groups over the previous 9 weeks. Food frequency was based on the number of times each food was consumed per day, week or month. The serving sizes consumed were estimated through the standard weight of food items or by determining the portion sizes by looking at a book containing over 500 photographs of food [54]. Energy (kcal) and macronutrient (g) consumption was determined by dividing the reported intake by the frequency in days using a validated software package (Easy $\operatorname{diet}^{\circledR}$, online version 2020) [55]. The total energy and macronutrient intake per kilogram of body mass was calculated for each athlete. The second method was a seven-day dietary recall collected the week prior to T1 and during the week of T2. This method was used to check if the results of the FFQ were similar to those of this recall [52].

\subsection{Statistical Analysis}

The data are shown as means and standard deviations. The Shapiro-Wilk test $(n<50)$ was used to determine normality. Likewise, the homoscedasticity assumption was tested with the previous Levene test. Thereafter, differences from T1 to T2 in each group separately were assessed using Student's $t$-tests for parametric paired data. Then, a two-way repeated-measures analysis of variance (ANOVA) test was performed to assess the interaction effects (time $\times$ supplementation group).

On the other hand, the percentage changes of the outcomes studied between T1 and T2 in each study group were calculated as $\Delta(\%):((\mathrm{T} 2-\mathrm{T} 1) / \mathrm{T} 1) \times 100)$. A one-way ANOVA test was performed to determine if there were significant differences between the means of the different outcomes analyzed among the 4 study groups. A Bonferroni post hoc test was applied for pairwise comparisons among supplemented groups to establish statistical significance levels.

Effect sizes as a qualitative measure were estimated by partial eta squared $\left(\eta^{2} p\right)$. Given that this measure overestimates effect sizes, the values were interpreted based on Ferguson, who indicated no effect if $0 \leq \eta^{2} p<0.05$, minimum effect if $0.05 \leq \eta^{2} p<0.26$, moderate effect if $0.26 \leq \eta^{2} p<0.64$ and strong effect if $\eta^{2} p \geq 0.64$ [56].

The analyses were completed by SPSS ${ }^{\circledR}$ software version 24.0 (SPSS, Inc., Chicago, IL, USA) and Microsoft Excel ${ }^{\circledR}$ version 24 (Microsoft Corporation, Redmond, WA, USA) and graphics using GraphPad Prism 6 software (GraphPad Software, Inc., San Diego, CA, USA). Statistical significance was designated when $p<0.05$.

\section{Results}

During the trial, the triathletes did not present significant statistical differences $(p>0.05)$ in energy and macronutrient intake values among groups (Table 3$)$. 
Table 3. Energy and macronutrient intake of triathletes during 9 weeks of study.

\begin{tabular}{lcccc}
\hline & PLG & CITG & BRG & CIT + BRG \\
\hline Energy $(\mathrm{kcal} / \mathrm{kg})$ & $45 \pm 6.4$ & $45.2 \pm 6.8$ & $44.9 \pm 6.5$ & $45.3 \pm 7.2$ \\
\hline Protein $(\mathrm{g} / \mathrm{kg})$ & $1.4 \pm 0.5$ & $1.5 \pm 0.7$ & $1.4 \pm 0.8$ & $1.4 \pm 0.5$ \\
\hline Fat $(\mathrm{g} / \mathrm{kg})$ & $1.4 \pm 0.4$ & $1.5 \pm 0.5$ & $1.4 \pm 0.6$ & $1.5 \pm 0.6$ \\
\hline Carbohydrates $(\mathrm{g} / \mathrm{kg})$ & $7.0 \pm 1.0$ & $7.1 \pm 1.2$ & $7.1 \pm 1.4$ & $7.0 \pm 1.3$ \\
\hline
\end{tabular}

Data are shown as mean \pm standard deviation. PLG: placebo group, CITG: citrulline group, BRG: $\mathrm{NO}_{3}{ }^{-}$group CIT-BRG: citrulline plus $\mathrm{NO}_{3}{ }^{-}$supplemented group.

Body mass, BMI, muscle mass and fat mass percentage did not present significant differences $(p>0.05)$ in the interaction group-by-time (Table 4).

Table 4. Anthropometry and body composition outcomes of triathletes.

\begin{tabular}{|c|c|c|c|c|}
\hline Group & T1 & $\mathrm{T} 2$ & $p(\mathrm{~T} \times \mathrm{G})$ & $\eta^{2} p$ \\
\hline \multicolumn{5}{|c|}{ Body mass (Kg) } \\
\hline PLG & $76.36 \pm 7.03$ & $76.31 \pm 6.76$ & \multirow{4}{*}{0.582} & \multirow{4}{*}{0.074} \\
\hline CITG & $79.08 \pm 7.36$ & $77.70 \pm 7.09$ & & \\
\hline BRG & $74.11 \pm 6.93$ & $74.00 \pm 6.90$ & & \\
\hline $\mathrm{CIT}+\mathrm{BRG}$ & $74.19 \pm 11.26$ & $74.29 \pm 11.38$ & & \\
\hline \multicolumn{5}{|c|}{ BMI $\left(k g / m^{2}\right)$} \\
\hline PLG & $24.01 \pm 1.89$ & $23.98 \pm 2.03$ & \multirow{4}{*}{0.407} & \multirow{4}{*}{0.115} \\
\hline CITG & $24.52 \pm 2.53$ & $23.99 \pm 2.25$ & & \\
\hline BRG & $23.25 \pm 1.86$ & $23.25 \pm 1.85$ & & \\
\hline CIT + BRG & $22.54 \pm 1.63$ & $22.53 \pm 1.59$ & & \\
\hline \multicolumn{5}{|c|}{ Muscle mass (kg) } \\
\hline PLG & $69.39 \pm 5.42$ & $69.65 \pm 5.73$ & \multirow{4}{*}{0.406} & \multirow{4}{*}{0.112} \\
\hline CITG & $72.35 \pm 6.21$ & $66.05 \pm 5.77$ & & \\
\hline BRG & $67.38 \pm 6.46$ & $67.95 \pm 6.31$ & & \\
\hline CIT + BRG & $68.49 \pm 9.49$ & $68.49 \pm 9.20$ & & \\
\hline \multicolumn{5}{|c|}{ Fat mass (\%) } \\
\hline PLG & $9.01 \pm 2.05$ & $8.66 \pm 2.14$ & \multirow{4}{*}{0.121} & \multirow{4}{*}{0.203} \\
\hline CITG & $8.45 \pm 1.44$ & $7.77 \pm 1.32$ & & \\
\hline BRG & $9.07 \pm 2.09$ & $8.18 \pm 0.96$ & & \\
\hline $\mathrm{CIT}+\mathrm{BRG}$ & $7.52 \pm 1.66$ & $7.58 \pm 2.17$ & & \\
\hline
\end{tabular}

Data are presented as mean \pm standard deviation. $p(\mathrm{~T} \times \mathrm{G})$ : interaction group-by-time $(p<0.05)$ by two-factor repeated-measures ANOVA.

Figure 1 shows the distance covered in the Cooper test at both T1 and T2. Significant differences can be seen in the group-by-time interaction in this parameter $(p=0.002$; $\left.\eta^{2} p=0.418\right)$. In addition, significant increases $(p<0.05)$ were observed between study moments in distance covered (T1: $2953.1 \pm 372.7$ vs. T2: $3079.6 \pm 423.5 \mathrm{~m}$ ) in CIT-BRG. 


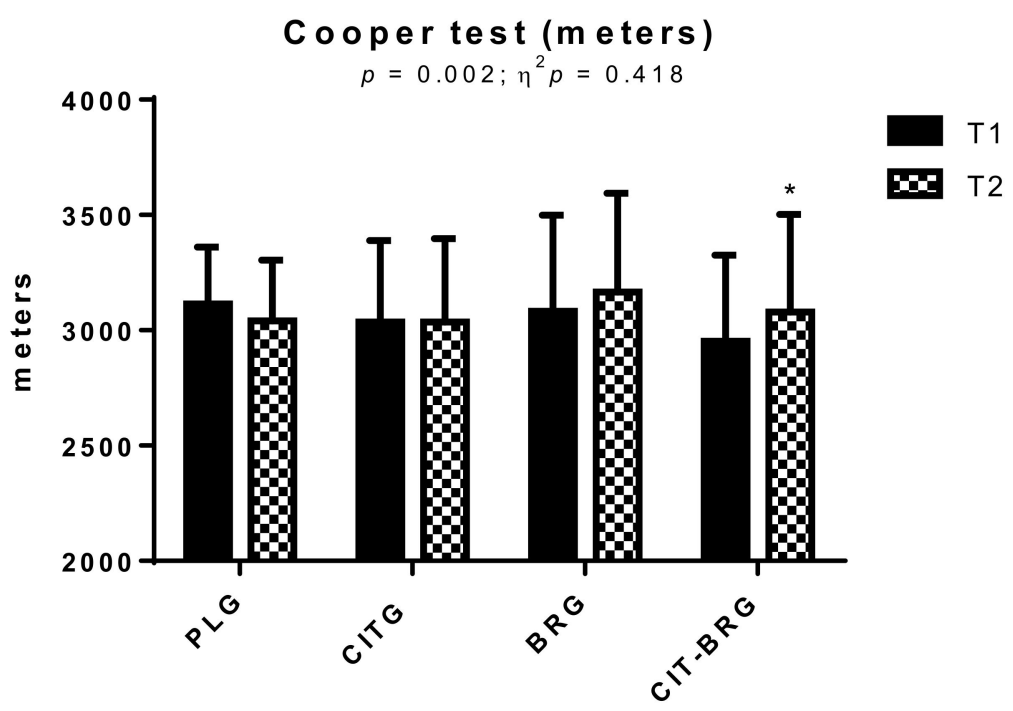

Figure 1. Distance covered in Cooper test by triathletes at T1 and T2 (after 9 weeks of supplementation). Data are presented as mean \pm standard deviation. *: Significant differences with respect to T1. $p<0.05$.

The EIMD markers did not present significant differences $(p>0.05)$ in the group-bytime interaction (Table 5). However, significant differences were observed between T1 and T2 for BR in creatinine (T1: $0.92 \pm 0.11$ vs. T2: $0.88 \pm 0.09 \mathrm{mg} / \mathrm{dL} ; \eta^{2} p: 0.063$ ) and LDH (T1: $445.38 \pm 247.59$ vs. T2: $\left.393.88 \pm 63.37 \mathrm{UI} / \mathrm{L} ; \eta^{2} p: 0.083\right)$.

Table 5. Serum EIMD markers of triathletes at T1 and T2 (after 9 weeks).

\begin{tabular}{|c|c|c|c|c|}
\hline Group & T1 & $\mathrm{T} 2$ & $p(\mathrm{~T} \times \mathrm{G})$ & $\eta^{2} p$ \\
\hline \multicolumn{5}{|c|}{ Urea (mg/dL) } \\
\hline PLG & $37.38 \pm 6.63$ & $38.00 \pm 4.81$ & \multirow{5}{*}{0.260} & \multirow{5}{*}{0.131} \\
\hline CITG & $37.06 \pm 6.92$ & $34.58 \pm 8.72$ & & \\
\hline $\mathrm{BRG}$ & $38.38 \pm 4.03$ & $37.50 \pm 2.83$ & & \\
\hline $\mathrm{CIT}+\mathrm{BRG}$ & $36.75 \pm 8.55$ & $41.13 \pm 6.06$ & & \\
\hline \multicolumn{3}{|c|}{ Creatinine (mg/dL) } & & \\
\hline PLG & $0.91 \pm 0.10$ & $0.92 \pm 0.10$ & \multirow{5}{*}{0.601} & \multirow{5}{*}{0.063} \\
\hline CITG & $0.93 \pm 0.57$ & $0.92 \pm 0.11$ & & \\
\hline $\mathrm{BRG}$ & $0.92 \pm 0.11$ & $0.88 \pm 0.09$ & & \\
\hline $\mathrm{CIT}+\mathrm{BRG}$ & $0.91 \pm 0.09$ & $0.91 \pm 0.11$ & & \\
\hline & & T (UI/L) & & \\
\hline PLG & $33.50 \pm 9.06$ & $37.13 \pm 16.31$ & \multirow{5}{*}{0.321} & \multirow{5}{*}{0.115} \\
\hline CITG & $30.50 \pm 9.09$ & $24.38 \pm 3.93$ & & \\
\hline $\mathrm{BRG}$ & $39.38 \pm 17.39$ & $29.36 \pm 4.79$ & & \\
\hline $\mathrm{CIT}+\mathrm{BRG}$ & $37.38 \pm 12.02$ & $29.75 \pm 7.91$ & & \\
\hline & & T (UI/L) & & \\
\hline PLG & $28.00 \pm 14.25$ & $29.63 \pm 13.76$ & \multirow{5}{*}{0.327} & \multirow{5}{*}{0.114} \\
\hline CITG & $25.88 \pm 9.43$ & $22.00 \pm 5.40$ & & \\
\hline BRG & $36.25 \pm 29.36$ & $23.38 \pm 8.45$ & & \\
\hline $\mathrm{CIT}+\mathrm{BRG}$ & $33.25 \pm 19.83$ & $22.63 \pm 7.65$ & & \\
\hline & & T (UI/L) & & \\
\hline PLG & $16.88 \pm 4.55$ & $18.50 \pm 6.37$ & \multirow{4}{*}{0.699} & \multirow{4}{*}{0.049} \\
\hline CITG & $18.88 \pm 8.04$ & $19.88 \pm 8.94$ & & \\
\hline $\mathrm{BRG}$ & $15.50 \pm 3.46$ & $18.63 \pm 6.41$ & & \\
\hline $\mathrm{CIT}+\mathrm{BRG}$ & $19.75 \pm 5.92$ & $20.25 \pm 8.78$ & & \\
\hline
\end{tabular}


Table 5. Cont.

\begin{tabular}{lcccc}
\hline \multicolumn{1}{c}{ Group } & T1 & T2 & $p(\mathbf{T} \times \mathbf{G})$ & $\eta^{2} p$ \\
\hline PLG & LDH (UI/L) & \\
CITG & $438.86 \pm 48.13$ & $367.38 \pm 77.77$ & \\
BRG & $330.88 \pm 90.99^{\mathrm{a}}$ & $324.00 \pm 71.97$ & 0.498 & 0.083 \\
CIT + BRG & $445.38 \pm 247.59^{\mathrm{b}}$ & $393.88 \pm 35.79 *$ & \\
& $431.00 \pm 75.05$ & $411.88 \pm 63.37$ & \\
\hline PLG & $319.50 \pm 297.34$ & CK (UI/L) & \\
CITG & $327.63 \pm 287.07$ & $175.00 \pm 51.77$ & \\
BRG & $328.38 \pm 247.59$ & $208.88 \pm 60.78$ & 0.138 \\
CIT + BRG & $379.38 \pm 336.75$ & $288.25 \pm 209.86$ & &
\end{tabular}

Data are presented as mean \pm standard deviation. $p(\mathrm{~T} \times \mathrm{G})$ : interaction group-by-time $(p<0.05)$ by two-way repeated-measures ANOVA. *: Significant differences between the two phases (T1 vs. T2) $(p<0.05)$. ${ }^{\text {: }}$ Significant differences with respect to PLG $(p<0.05) .{ }^{\mathrm{b}}$ : Significant differences with respect to CITG $(p<0.05)$.

Table 5 displays significant differences in the group-by-time interaction for cortisol $\left(p=0.044 ; \eta^{2} p=0.247\right)$ and T/C $\left(p=0.005 ; \eta^{2} p=0.359\right)$. In this sense, a significant difference was observed for T/C in CIT-BRG with respect to PLG at T2. On the other hand, a significant decrease in testosterone levels and T/C was observed in PLG, CITG and BRG after 9 weeks of supplementation (Table 6).

Table 6. Testosterone and cortisol status and testosterone/cortisol ratio of the triathletes at T1 and T2 (after 9 weeks).

\begin{tabular}{|c|c|c|c|c|}
\hline Group & T1 & T2 & $p(\mathrm{~T} \times \mathrm{G})$ & $\eta^{2} p$ \\
\hline \multicolumn{5}{|c|}{ Testosterone (ng/mL) } \\
\hline PLG & $7.66 \pm 2.26$ & $4.51 \pm 1.21^{*}$ & \multirow{5}{*}{0.116} & \multirow{5}{*}{0.188} \\
\hline CITG & $7.77 \pm 1.10$ & $5.50 \pm 1.36$ * & & \\
\hline BRG & $7.11 \pm 1.26$ & $4.92 \pm 1.16^{*}$ & & \\
\hline $\mathrm{CIT}+\mathrm{BRG}$ & $7.55 \pm 1.06$ & $6.69 \pm 2.50$ & & \\
\hline & & sol $(\mu \mathrm{g} / \mathrm{dL})$ & & \\
\hline PLG & $15.76 \pm 1.34$ & $20.37 \pm 3.47^{*}$ & \multirow{5}{*}{0.044} & \multirow{4}{*}{0.247} \\
\hline CITG & $16.03 \pm 2.48$ & $18.20 \pm 3.80$ & & \\
\hline BRG & $15.89 \pm 3.19$ & $17.84 \pm 3.76$ & & \\
\hline $\mathrm{CIT}+\mathrm{BRG}$ & $16.94 \pm 2.33$ & $15.30 \pm 5.53$ & & \\
\hline \multicolumn{4}{|c|}{ Testosterone/cortisol ratio } & \\
\hline PLG & $49.07 \pm 15.92$ & $22.87 \pm 8.12 *$ & \multirow{4}{*}{0.005} & \multirow{4}{*}{0.359} \\
\hline CITG & $49.13 \pm 7.84$ & $31.25 \pm 11.02 *$ & & \\
\hline BRG & $46.95 \pm 13.83$ & $28.63 \pm 8.38 *$ & & \\
\hline $\mathrm{CIT}+\mathrm{BRG}$ & $45.97 \pm 13.16$ & $51.66 \pm 30.00^{\mathrm{a}}$ & & \\
\hline
\end{tabular}

Data are presented as mean \pm standard deviation. $p(\mathrm{~T} \times \mathrm{G})$ : group-by-time interaction $(p<0.05)$ by two-way repeated-measures ANOVA. *: Significant differences between the two phases (T1 vs. T2) $(p<0.05)$. ${ }^{\text {: }}$ Significant differences with respect to PLG $(p<0.05)$.

Figure 2 shows the percentage change in distance covered in the Cooper test for each of the study groups. Significant differences can be observed in this parameter $(p=0.002$; $\left.\eta^{2} p=0.424\right)$. Concretely, CIT-BRG presented a significantly higher value in the $\%$ change than PLG and CITG $(p<0.05)$. 
$\triangle$ D istance covered

$p=0.002 ; \eta^{2} p=0.424$

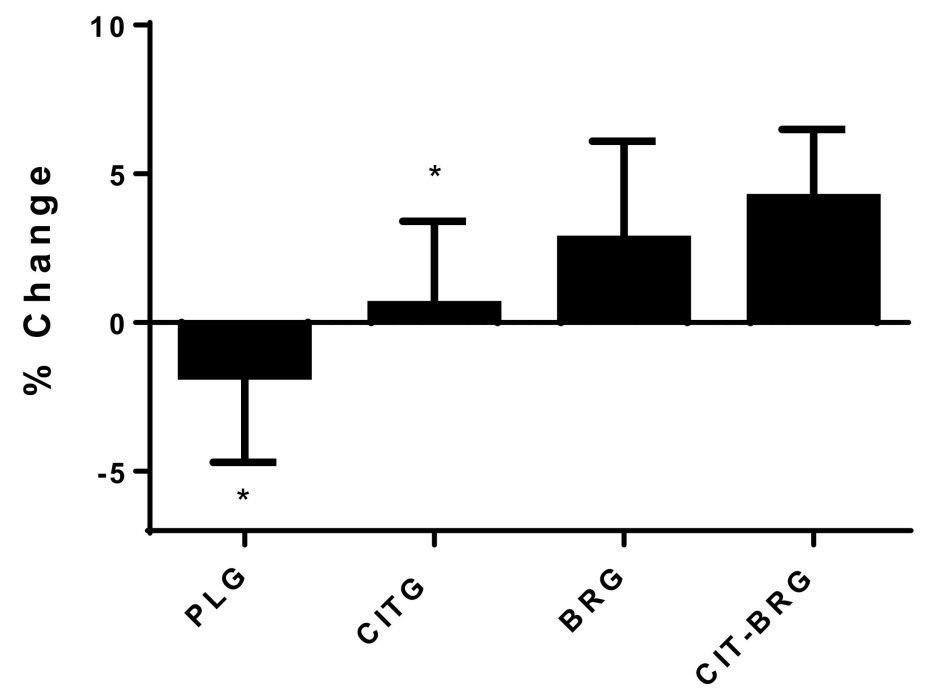

Figure 2. Percentage changes during the study in estimated distance covered in Cooper test in groups. Data are presented as mean \pm standard deviation. $\Delta:((\mathrm{T} 2-\mathrm{T} 1) / \mathrm{T} 1) \times 100$. *: Significant differences with respect to CIT-BRG. $p<0.05$.

Figure 3 indicates significant differences in cortisol percentage change $(p=0.049$; $\eta^{2} p=0.257$ ) between PLG and CIT-BRG. Moreover, T/C percentage change presented statistically significant differences $\left(p=0.018 ; \eta^{2} p=0.297\right)$ between CIT-BRG and PLG. In the case of testosterone, there were no significant differences among groups in percentage change $(p=0.149)$.

$\Delta$ Testosterone and Cortisol Status

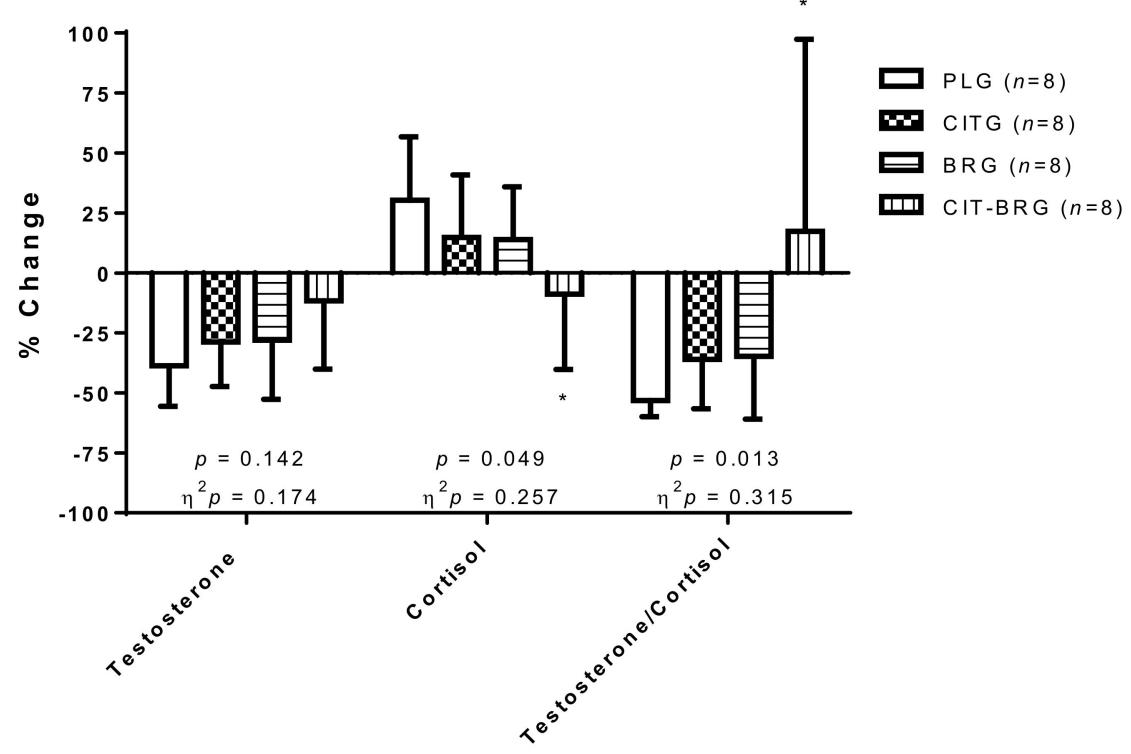

Figure 3. Percentage changes during the study in cortisol and testosterone hormone status and testosterone/cortisol ratio in the triathletes. Data are presented as mean \pm standard deviation. $\Delta:((\mathrm{T} 2-\mathrm{T} 1) / \mathrm{T} 1) \times 100 . *$ : Significant differences with respect to PLG. $p<0.05$. 


\section{Discussion}

This study was planned to assess the effect of long-term (9 weeks) combination of $3 \mathrm{~g} /$ day of CIT plus $2.1 \mathrm{~g} /$ day of $\mathrm{BR}\left(300 \mathrm{mg} /\right.$ day of $\left.\mathrm{NO}_{3}{ }^{-}\right)$supplementation on recovery status by distance covered in the Cooper test, serum EIMD markers and testosterone and cortisol in male triathletes. The EIMD markers (urea, creatinine, AST, ALT, GGT, LDH, CK) did not show any significant differences in the group-by-time interaction. However, triathletes showed a significantly better group-by-time interaction in distance covered in the Cooper test and anabolic/catabolic hormone status in CIT-BRG by preventing an increase in cortisol and a better T/C ratio. Furthermore, while CITG and BRG showed a significant decrease in testosterone levels, CIT + BR supplementation prevented a decline of this anabolic hormone. These significant results could be motivated by the synergistic effect that both supplements provided on the variables used to determine recovery status.

The balance between training loads and recovery are key factors in improving athletic performance [4]. To assess and control this balance, and with the intention of avoiding fatigue and maintaining an adequate performance, there are numerous parameters utilized, such as EIMD markers and anabolic/catabolic hormones [57,58]. Although there is an acute intensification of EIMD markers after exercise [2,59], long-term maintenance of high EIMD values could indicate a chronic fatigue status and inadequate adaptation to training [60]. In addition, it has been observed that anabolic/catabolic hormone status is changed after exercise due to an acute effect $[58,61]$. However, long-term variations in these hormones may be indicators of an adequate endogenous adaptation or, on the contrary, a fatigue status and, therefore, of an impaired sports performance [6]. Testosterone is an anabolic and androgenic hormone secreted by the hypothalamic-pituitary-testicular axis, and its increase specifies an overall anabolic state [62]. Nevertheless, cortisol, secreted by the hypothalamic-pituitary-adrenal axis, is a steroid hormone considered as a factor that indicates accumulated stress, and therefore, its increase suggests an accumulation of stress or catabolism [63]. Consequently, an increase in testosterone and/or a decrease in cortisol would lead to an increase in the testosterone/cortisol ratio, as an indicator of adaptation to training, thus indicating better endogenous recovery, while a decrease would indicate fatigue status $[61,64]$. In order to achieve these effects, some supplements that promote the NO pathway, such as CIT and BR, have been proposed [31].

It has been shown that NO can enhance recovery status through certain mechanisms [65], such as increasing protein synthesis through vasodilation of the arteries and veins of skeletal muscle that improve nutrient flow to the muscles, which in the long term favors muscle growth and repair [66]. In addition, it has been suggested that NO probably promotes angiogenesis in tissues by regulating the expression of the vascular endothelial growth factor [67]. Moreover, it has been demonstrated that skeletal muscle has the capacity to store, transport and metabolize $\mathrm{NO}_{3}{ }^{-}$and $\mathrm{NO}_{2}{ }^{-}$[68]. Therefore, chronic supplementation with NO precursor supplements (CIT and $\mathrm{BR}$ ) would increase the levels of $\mathrm{NO}_{3}{ }^{-}$ stored in skeletal muscle that is beneficial for NO production [69]. All these mentioned mechanisms could probably work in a complementary manner by enhancing endogenous recovery. A more efficient production of energy during exercise would reduce fatigue and thus decrease EIMD through an increase in protein synthesis [70]. This improved regeneration would lead to a decrease in stress and thus a reduced catabolic state, which would be reflected in anabolic/catabolic hormones [11].

In addition to the effect on NO, the CIT has been found to stimulate muscle protein synthesis by activating mTOR through the PI3K/MAPK/4E-BP1 pathway [71] and by increasing ARG production, which promotes growth hormone secretion [72]. Likewise, increased ARG production will improve intramuscular creatine levels, which will also allow an increase in phosphocreatine reserves, contributing to energy supply through a more efficient ATP regeneration and lowering fatigue, resulting in a decrease in EIMD after a high-demanding training [31]. Moreover, being part of the urea cycle, CIT facilitates the functioning of this cycle, helping to reduce the accumulation of ammonium and blood 
lactate concentration, improving the clearance capacity of these substances and, therefore, reducing the fatigue caused by their accumulation [73].

To the authors' knowledge, the effects of long-term combination of CIT plus BR supplementation on EIMD markers have not been studied in depth [74]. In this sense, the present trial did not present significant differences in the interaction between group and time in EIMD markers (urea, creatinine, AST, ALT, GGT, LDH and CK) $(p>0.05$; Table 4). In the same line, some investigations that have evaluated the acute effects of these supplements individually have not found improvements in EIMD markers. Daab et al. did not find significant differences in CK and LDH before the Loughborough Intermittent Shuttle Test between the supplemented and the placebo groups after 7 days ( 3 days preexercise, test day and 3 days post-exercise) with $150 \mathrm{~mL}$ of $\mathrm{BR}$ juice $\left(250 \mathrm{mg}\right.$ of $\mathrm{NO}_{3}{ }^{-}$) taken in two intakes per day (08:00 and 18:00 h) in soccer players [74]. Likewise, MartínezSanchez et al. did not present significant differences in the biochemical markers AST, ALT and CK between the supplemented group and placebo with CIT-enriched watermelon juice ( $3.45 \mathrm{~g}$ per $500 \mathrm{~mL} /$ day) taken two hours before a half-marathon race [66]. Therefore, considering that the results of this study did not offer any beneficial effects on the EIMD markers, the results obtained by the combination of CIT plus BR in the present study dismantle the original hypothesis in which it was predicted that both supplements could work in a complementary manner by reducing EIMD.

Although, to the authors' knowledge, the effects of long-term combination of CIT plus BR supplementation on anabolic/catabolic hormones have not been studied, in the current study, the combination of these supplements showed a better group-by-time interaction in distance covered in the Cooper test and anabolic/catabolic hormone status in CIT-BRG (Table 5 and Figure 3 ) by preventing an increase in cortisol $\left(p=0.044 ; \eta^{2} p=0.247\right)$ and a better $\mathrm{T} / \mathrm{C}$ ratio $\left(p=0.005 ; \eta^{2} p=0.359\right)$. Furthermore, while CITG and BRG showed a significant decrease in the testosterone level after 9 weeks $(p<0.05)$, CIT + BR supplementation prevented a decline in this anabolic hormone. Nevertheless, some authors have shown the effect of both supplements individually on these hormones. In this way, Da Silva et al. did not observe improvements in the $\mathrm{T} / \mathrm{C}$ ratio during the recovery period at 24,48 and $72 \mathrm{~h}$ post-exercise in untrained young adult men after $6 \mathrm{~g}$ CIT supplementation before a $60 \mathrm{~min}$ workout [27]. These authors indicated that the inability to improve anabolic factors results in no beneficial effect of CIT supplementation on muscle regeneration during an acute recovery period. However, the chronic changes in cortisol and testosterone can be related to accumulated stress and body regeneration during the sports season [6]. In this way, Garnacho-Castaño et al. showed that BR supplementation did not appear to influence anabolic/catabolic status in response to acute high-intensity workouts after drinking $140 \mathrm{~mL}$ of $\mathrm{BJ}\left(\sim 12.8 \mathrm{mmol} \mathrm{NO}_{3}{ }^{-}\right)$[25]. On the contrary, in this study, CITG and BRG presented a maintenance of distance covered in the Cooper test and a decrease in testosterone levels and $\mathrm{T} / \mathrm{C}$ after 9 weeks of supplementation. These data could indicate an inadequate recovery status in these groups because after 9 weeks with adequate training, a better sports performance would be expected. Nevertheless, this study presented a significantly better recovery status in CIT-BRG represented as an increase in distance covered in the Cooper test and maintenance of testosterone and $\mathrm{T} / \mathrm{C}$ ratio after 9 weeks of combined supplementation. These adaptations were obtained by preventing an increase in cortisol and/or a decline in testosterone in CIT-BRG with respect to other supplementation groups.

In this sense, CIT is a key activator of muscle protein synthesis in catabolic situations, such as high-intensity training periods, via activation of the mTOR pathway due to its key role in the regulation of nitrogen homeostasis [75]. Likewise, testosterone increases mTOR pathway [76] and cortisol inhibits mTOR pathway signaling [75]. Thus, increasing testosterone and controlling cortisol secretion could result in lower stress and adequate muscle regeneration [6]. In this sense, the long-term effect of CIT enhancing NO could increase blood flow in the testis promoting testosterone synthesis [19] and maintaining the testosterone level by vasodilator effect [77]. In addition, the enhancement of NO reduces ACTH-mediated cortisol production [18]. Consequently, although this hypothesis is spec- 
ulative, increasing $\mathrm{NO}$ could be successful in maintaining an anabolic state, decreasing metabolic stress [2,9]. Therefore, the results obtained in the CIT-BRG group could show how independent pathways in muscle recovery (NO and mTOR) can be synergistically activated with both supplements to obtain better results.

\subsection{Limitations, Strengths and Future Research}

It should be noted that it is difficult to obtain larger samples in athletes as not many of them have the availability to comply with the training and supplementation instructions required by the study. In addition, the effects that both supplements used could have on the muscle were speculative because no evaluation was included in this regard. On the other hand, sampling using a convenient, non-probabilistic sampling procedure may produce results that are not representative of the rest of the population. These limitations may underrepresent the results and may affect study outcomes. For this reason, the results should be considered in the context of the study. However, the methodology used in this trial, a double-blind, placebo-controlled trial, is the most important strength. In addition, another strength was the control of the triathletes' diet, as well as the control of the body composition throughout the intervention process, so that these outcomes did not influence the final results. Another strength is the synergistic potential of the study.

Future research should continue to study the long-term effects of this combination on recovery, using different markers, such as sports performance, in order to expand the existing knowledge on this combination. It should also examine the effectiveness of these supplements in athletes who have already been diagnosed with an overtraining state to determine whether the use of these supplements as part of treatment would accelerate recovery. In addition, it should analyze how this potential combination affects the female population or anaerobic sports, given that this study only focused on males and measured aerobic performance.

\subsection{Practical Application}

This research could be of interest to physicians and nutritionists who want to achieve better post-exercise recovery for their athletes. Considering that $3 \mathrm{~g} /$ day of CIT plus $2.1 \mathrm{~g} /$ day of $\mathrm{BR}\left(300 \mathrm{mg} /\right.$ day of $\left.\mathrm{NO}_{3}{ }^{-}\right)$for 9 weeks could advance muscle and endogenous recovery, supplementation phases could be considered in the intensive training phases.

\section{Conclusions}

In conclusion, although the combination of $3 \mathrm{~g} /$ day of CIT plus $2.1 \mathrm{~g} /$ day of BR (300 mg/day of $\mathrm{NO}_{3}{ }^{-}$) supplementation for 9 weeks did not present any benefit for EIMD, it prevented an increase in cortisol and a decline in T/C compared with placebo or isolated supplementation. Moreover, this combination promoted a better distance covered in the Cooper test after 9 weeks of supplementation. Therefore, the combined use of $3 \mathrm{~g} /$ day of CIT and BR (300 mg/day of $\left.\mathrm{NO}_{3}{ }^{-}\right)$could promote a faster muscle recovery status but without preventing EIMD.

Author Contributions: All authors have read and agreed to the published version of the manuscript. J.B. and J.M.-A.: conception and design of research, analysis and interpretation of the data, drafting of the paper, critical review and approval of the final version submitted for publication. J.C.-G. and A.V.: analysis and interpretation of the data, drafting of the paper, critical review and approval of the final version submitted for publication. D.F.-L., J.O.-I. and J.S.-C.: drafting of the paper, critical review and approval of the final version submitted for publication.

Funding: The authors declare no funding sources.

Institutional Review Board Statement: This trial was designed in accordance with the Declaration of Helsinki (2008) and the Fortaleza update (2013) [47] and was approved by the Human Research Ethics Committee of the University of León, Spain (number: ULE-020-2020). 
Informed Consent Statement: All triathletes were completely informed of all actions of the study and signed the personal statement of informed consent, giving their individual agreement to take part in the proposed work.

Data Availability Statement: No new data were created or analyzed in this study. Data sharing is not applicable to this article.

Acknowledgments: The authors want to thank the triathletes and other assistants involved in this investigation for their participation, enthusiasm and cooperation.

Conflicts of Interest: The authors affirm no conflict of interest.

\section{References}

1. Del Coso, J.; González, C.; Abian-Vicen, J.; Salinero Martín, J.J.; Soriano, L.; Areces, F.; Ruiz, D.; Gallo, C.; Lara, B.; Calleja-González, J. Relationship between physiological parameters and performance during a half-ironman triathlon in the heat. J. Sports Sci. 2014, 32, 1680-1687. [CrossRef]

2. Fernández-Landa, J.; Fernández-Lázaro, D.; Calleja-González, J.; Caballero-García, A.; Córdova, A.; León-Guereño, P.; MielgoAyuso, J. Long-Term Effect of Combination of Creatine Monohydrate Plus $\beta$-Hydroxy $\beta$-Methylbutyrate (HMB) on ExerciseInduced Muscle Damage and Anabolic/Catabolic Hormones in Elite Male Endurance Athletes. Biomolecules 2020, 10, 140. [CrossRef]

3. Neubauer, O.; König, D.; Wagner, K.H. Recovery after an Ironman triathlon: Sustained inflammatory responses and muscular stress. Eur. J. Appl. Physiol. 2008, 104, 417-426. [CrossRef]

4. Meeusen, R.; Duclos, M.; Foster, C.; Fry, A.; Gleeson, M.; Nieman, D.; Raglin, J.; Rietjens, G.; Steinacker, J.; Urhausen, A. Prevention, diagnosis and treatment of the overtraining syndrome: Joint consensus statement of the European College of Sport Science (ECSS) and the American College of Sports Medicine (ACSM). Eur. J. Sport Sci. 2013, 13, 1-24. [CrossRef]

5. Del Coso, J.; Areces, F.; Salinero, J.J.; González-Millán, C.; Abián-Vicén, J.; Soriano, L.; Ruiz, D.; Gallo, C.; Lara, B.; Calleja-Gonzalez, J. Compression stockings do not improve muscular performance during a half-ironman triathlon race. Eur. J. Appl. Physiol. 2014, 114, 587-595. [CrossRef]

6. Mielgo-Ayuso, J.; Zourdos, M.C.; Urdampilleta, A.; Calleja-González, J.; Seco, J.; Córdova, A. Relationship of long-term macronutrients intake on anabolic-catabolic hormones in female elite volleyball players. Nutr. Hosp. 2017, 34, 1155-1162. [CrossRef]

7. Hotfiel, T.; Mayer, I.; Huettel, M.; Hoppe, M.W.; Engelhardt, M.; Lutter, C.; Pöttgen, K.; Heiss, R.; Kastner, T.; Grim, C. Accelerating Recovery from Exercise-Induced Muscle Injuries in Triathletes: Considerations for Olympic Distance Races. Sports $2019,7,143$. [CrossRef]

8. Bescós, R.; Sureda, A.; Tur, J.A.; Pons, A. The effect of nitric-oxide-related supplements on human performance. Sports Med. 2012, 42, 99-117. [CrossRef]

9. Beck, K.L.; Thomson, J.S.; Swift, R.J.; von Hurst, P.R. Role of nutrition in performance enhancement and postexercise recovery. Open Access J. Sport. Med. 2015, 6, 259. [CrossRef]

10. Bryan, N.S. Safe and Effective Use of Nitric Oxide-Based Supplements and Nutrition for Sports Performance, 2nd ed.; Elsevier Inc.: Amsterdam, The Netherlands, 2018.

11. Gonzalez, A.M.; Trexler, E.T. Effects of Citrulline Supplementation on Exercise Performance in Humans: A Review of the Current Literature. J. Strength Cond. Res. 2020, 34, 1480-1495. [CrossRef]

12. Gilligan, D.M.; Panza, J.A.; Kilcoyne, C.M.; Waclawiw, M.A.; Casino, P.R.; Quyyumi, A.A. Contribution of endothelium-derived nitric oxide to exercise-induced vasodilation. Circulation 1994, 90, 2853-2858. [CrossRef]

13. Anderson, J.E. A Role for Nitric Oxide in Muscle Repair: Nitric Oxide-Mediated Activation of Muscle Satellite Cells. Mol. Biol. Cell 2000, 11, 1859-1874. [CrossRef]

14. Arazi, H.; Eghbali, E. Possible Effects of beetroot Supplementation on Physical Performance Through Metabolic, Neuroendocrine, and Antioxidant Mechanisms: A Narrative Review of the Literature. Front. Nutr. 2021, 8, 660150. [CrossRef]

15. Viribay, A.; Arribalzaga, S.; Mielgo-Ayuso, J.; Castañeda-Babarro, A.; Seco-Calvo, J.; Urdampilleta, A. Effects of 120 g/h of carbohydrates intake during a mountain marathon on exercise-induced muscle damage in elite runners. Nutrients 2020, $12,1367$. [CrossRef]

16. Urdampilleta, A.; Arribalzaga, S.; Viribay, A.; Castañeda-Babarro, A.; Seco-Calvo, J.; Mielgo-Ayuso, J. Effects of 120 vs. 60 and $90 \mathrm{~g} / \mathrm{h}$ Carbohydrate Intake during a Trail Marathon on Neuromuscular Function and High Intensity Run Capacity Recovery. Nutrients 2020, 12, 94. [CrossRef]

17. Wang, J.M.; Gu, C.H.; Tao, L.; Wu, X.L. Effect of surgery and efferent duct ligation on testicular blood flow and testicular steroidogenesis in the rat. J. Reprod. Fertil. 1985, 73, 191-196. [CrossRef]

18. Monau, T.R.; Vargas, V.E.; Zhang, L.; Myers, D.A.; Ducsay, C.A. Nitric oxide inhibits ACTH-induced cortisol production in near-term, long-term hypoxic ovine fetal adrenocortical cells. Reprod. Sci. 2010, 17, 955-962. [CrossRef]

19. Banihani, S.A. Biomolecules Testosterone in Males as Enhanced by Onion (Allium Cepa, L.). Biomolecules 2019, 9, 75. [CrossRef] 
20. Hernández, A.; Schiffer, T.A.; Ivarsson, N.; Cheng, A.J.; Bruton, J.D.; Lundberg, J.O.; Weitzberg, E.; Westerblad, H. Dietary nitrate increases tetanic [Ca 2+] i and contractile force in mouse fast-twitch muscle. J. Physiol. 2012, 590, 3575-3583. [CrossRef]

21. Milton-Laskibar, I.; Alfredo Martínez, J.; Portillo, M.P. Current knowledge on BRroot bioactive compounds: Role of nitrate and betalains in health and disease. Foods 2021, 10, 1314. [CrossRef]

22. Jones, L.; Bailey, S.J.; Rowland, S.N.; Alsharif, N.; Shannon, O.M.; Clifford, T. The Effect of Nitrate-Rich BRroot Juice on Markers of Exercise-Induced Muscle Damage: A Systematic Review and Meta-Analysis of Human Intervention Trials. J. Diet. Suppl. 2021. [CrossRef]

23. Clifford, T.; Bell, O.; West, D.J.; Howatson, G.; Stevenson, E.J. The effects of BRroot juice supplementation on indices of muscle damage following eccentric exercise. Eur. J. Appl. Physiol. 2016, 116, 353-362. [CrossRef]

24. Sarfaraz, S.; Ikram, R.; Osama, M.; Anser, H. Effect of different doses of lyophilized BRroot on fertility and reproductive hormones. Pak. J. Pharm. Sci. 2020, 33, 2505-2510. [CrossRef]

25. Garnacho-Castaño, M.V.; Palau-Salvà, G.; Serra-Payá, N.; Ruiz-Hermosel, M.; Berbell, M.; Viñals, X.; Bataller, M.G.; Carbonell, T.; Vilches-Saez, S.; Cobo, E.P.; et al. Understanding the effects of BRroot juice intake on CrossFit performance by assessing hormonal, metabolic and mechanical response: A randomized, double-blind, crossover design. J. Int. Soc. Sports Nutr. 2020, 17. [CrossRef]

26. Larsen, F.J.; Schiffer, T.A.; Borniquel, S.; Sahlin, K.; Ekblom, B.; Lundberg, J.O.; Weitzberg, E. Dietary Inorganic Nitrate Improves Mitochondrial Efficiency in Humans. Cell Metab. 2011, 13, 149-159. [CrossRef]

27. Da Silva, D.K.; Jacinto, J.L.; de Andrade, W.B.; Roveratti, M.C.; Estoche, J.M.; Balvedi, M.C.W.; de Oliveira, D.B.; da Silva, R.A.; Aguiar, A.F. Citrulline malate does not improve muscle recovery after resistance exercise in untrained young adult men. Nutrients 2017, 9, 1132. [CrossRef]

28. Haider, G.; Folland, J.P. Nitrate supplementation enhances the contractile properties of human skeletal muscle. Med. Sci. Sports Exerc. 2014, 46, 2234-2243. [CrossRef]

29. Radak, Z.; Naito, H.; Taylor, A.W.; Goto, S. Nitric oxide: Is it the cause of muscle soreness? Nitric Oxide Biol. Chem. 2012, 26, 89-94. [CrossRef]

30. Bahri, S.; Zerrouk, N.; Aussel, C.; Moinard, C.; Crenn, P.; Curis, E.; Chaumeil, J.C.; Cynober, L.; Sfar, S. Citrulline: From metabolism to therapeutic use. Nutrition 2013, 29, 479-484. [CrossRef]

31. Rhim, H.C.; Kim, S.J.; Park, J.; Jang, K.M. Effect of citrulline on post-exercise rating of perceived exertion, muscle soreness, and blood lactate levels: A systematic review and meta-analysis. J. Sport Health Sci. 2020, 9, 553-561. [CrossRef]

32. Mathiowetz, V.; Weber, K.; Volland, G.; Kashman, N. Reliability and validity of grip and pinch strength evaluations. J. Hand Surg. 1984, 9, 222-226. [CrossRef]

33. Fernández-Landa, J.; Fernández-Lázaro, D.; Calleja-González, J.; Caballero-García, A.; Martínez, A.C.; León-Guereño, P.; MielgoAyuso, J. Effect of ten weeks of creatine monohydrate plus HMB supplementation on athletic performance tests in elite male endurance athletes. Nutrients 2020, 12, 193. [CrossRef]

34. Allen, A.E.; Dupont, C.L.; Oborník, M.; Horák, A.; Nunes-Nesi, A.; McCrow, J.P.; Zheng, H.; Johnson, D.A.; Hu, H.; Fernie, A.R.; et al. Evolution and metabolic significance of the urea cycle in photosynthetic diatoms. Nature 2011, 473, 203-207. [CrossRef]

35. Alvares, T.S.; Conte-Junior, C.A.; Silva, J.T.; Paschoalin, V.M.F. L-arginine does not improve biochemical and hormonal response in trained runners after 4 weeks of supplementation. Nutr. Res. 2014, 34, 31-39. [CrossRef]

36. Le Roux-Mallouf, T.; Pelen, F.; Vallejo, A.; Halimaoui, I.; Doutreleau, S.; Verges, S. Effect of chronic nitrate and citrulline supplementation on vascular function and exercise performance in older individuals. Aging 2019, 11, 3315. [CrossRef]

37. Thomas, D.; Erdman, K.; Burke, L. American College of Sports Medicine Joint Position Statement. Nutrition and Athletic Performance. Med. Sci. Sports Exerc. 2016, 48, 543-568. [CrossRef]

38. Pruna, R.; Lizarraga, A.; Domínguez, D. Medical assessment in athletes. Med. Clin. 2018, 150, 268-274. [CrossRef]

39. Wax, B.; Kavazis, A.N.; Luckett, W. Effects of Supplemental Citrulline-Malate Ingestion on Blood Lactate, Cardiovascular Dynamics, and Resistance Exercise Performance in Trained Males. J. Diet. Suppl. 2016, 13, 269-282. [CrossRef]

40. Pérez-Guisado, J.; Jakeman, P.M. Citrulline malate enhances athletic anaerobic performance and relieves muscle soreness. $J$. Strength Cond. Res. 2010, 24, 1215-1222. [CrossRef]

41. Robineau, J.; Marrier, B.; Le Meur, Y.; Piscione, J.; Peeters, A.; Lacome, M. Road to Rio: A Case Study of Workload Periodization Strategy in Rugby-7s During an Olympic Season. Front. Sports Act. Living 2020, 1, 72. [CrossRef]

42. Anderson, O.K.; Martinez-Ferran, M.; Lorenzo-Calvo, J.; Jiménez, S.L.; Pareja-Galeano, H. Effects of Nitrate Supplementation on Muscle Strength and Mass: A Systematic Review. J. Strength Cond. Res. 2021. [CrossRef]

43. Hoon, M.W.; Johnson, N.A.; Chapman, P.G.; Burke, L.M. The effect of nitrate supplementation on exercise performance in healthy individuals: A systematic review and meta-analysis. Int. J. Sports Nutr. Exerc. Metab. 2013, 23, 522-532. [CrossRef]

44. Trexler, E.T.; Persky, A.M.; Ryan, E.D.; Schwartz, T.A.; Stoner, L.; Smith-Ryan, A.E. Acute Effects of Citrulline Supplementation on High-Intensity Strength and Power Performance: A Systematic Review and Meta-Analysis. Sports Med. 2019, 49, 707-718. [CrossRef]

45. Jones, A.M.; Thompson, C.; Wylie, L.J.; Vanhatalo, A. Dietary nitrate and physical performance. Ann. Rev. Nutr. 2018, 38, 303-328. [CrossRef]

46. Wehrens, S.M.T.; Christou, S.; Isherwood, C.; Middleton, B.; Gibbs, M.A.; Archer, S.N.; Skene, D.J.; Johnston, J.D. Meal Timing Regulates the Human Circadian System. Curr. Biol. 2017, 27, 1768. [CrossRef] 
47. Nowatzke, W.; Sarno, M.J.; Birch, N.C.; Stickle, D.F.; Eden, T.; Cole, T.G. Evaluation of an assay for serum 1,5-anhydroglucitol $\left(\right.$ GlycoMark $^{\mathrm{TM}}$ ) and determination of reference intervals on the Hitachi 917 analyzer. Clin. Chim. Acta 2004, 350, 201-209. [CrossRef]

48. Mehta, P.H.; Welker, K.M.; Zilioli, S.; Carré, J.M. Testosterone and cortisol jointly modulate risk-taking. Psychoneuroendocrinology 2015, 56, 88-99. [CrossRef]

49. Penry, J.T.; Wilcox, A.R.; Yun, J. Validity and reliability analysis of Cooper's 12-minute run and the multistage shuttle run in healthy adults. J. Strength Cond. Res. 2011, 25, 597-605. [CrossRef]

50. Alvero-Cruz, J.R.; Carnero, E.A.; Giráldez García, M.A.; Alacid, F.; Rosemann, T.; Nikolaidis, P.T.; Knechtle, B. Cooper Test Provides Better Half-Marathon Performance Prediction in Recreational Runners Than Laboratory Tests. Front. Physiol. 2019, 10, 1349. [CrossRef]

51. Da Silva, V.S.; Vieira, M.F.S. International society for the advancement of kinanthropometry (Isak) global: International accreditation scheme of the competent anthropometrist. Revista Brasileira de Cineantropometria Desempenho Humano 2020, 22, 1-6. [CrossRef]

52. Mielgo-Ayuso, J.; Maroto-Sánchez, B.; Luzardo-Socorro, R.; Palacios, G.; Gil-Antuñano, N.P.; González-Gross, M. EXERNET Study Group Evaluation of nutritional status and energy expenditure in athletes. Nutr. Hosp. 2015, 31, 227-236. [CrossRef]

53. Mielgo-Ayuso, J.; Zourdos, M.C.; Calleja-González, J.; Urdampilleta, A.; Ostojic, S.M. Dietary intake habits and controlled training on body composition and strength in elite female volleyball players during the season. Appl. Physiol. Nutr. Metab. 2015, 40, 827-834. [CrossRef]

54. Russolillo Femenías, G.; Marques-Lopes, I. Láminas de Porciones de Alimentos a Tamaño Real; Librería Proteo: Málaga, Spain, 2011

55. Valensise, H.; Andreoli, A.; Lello, S.; Magnani, F.; Romanini, C.; De Lorenzo, A. Total-body skeletal muscle mass: Development and cross-validation of anthropometric prediction models. Am. J. Clin. Nutr. 2000, 72, 796-803. [CrossRef]

56. Ferguson, C.J. An Effect Size Primer: A Guide for Clinicians and Researchers. Prof. Psychol. Res. Pract. 2009, 40, 532-538. [CrossRef]

57. Banfi, G.; Colombini, A.; Lombardi, G.; Lubkowska, A. Metabolic Markers in Sports Medicine, 1st ed.; Elsevier Inc.: Amsterdam, The Netherlands, 2012; Volume 56.

58. Baur, D.A.; Bach, C.W.; Hyder, W.J.; Ormsbee, M.J. Fluid retention, muscle damage, and altered body composition at the Ultraman triathlon. Eur. J. Appl. Physiol. 2016, 116, 447-458. [CrossRef]

59. Danielsson, T.; Rg Carlsson, J.; Schreyer, H.; Ahnesjö, J.; Ten Siethoff, L.; Ragnarsson, T.; Tugetam, Å.; Bergman, P. Blood biomarkers in male and female participants after an Ironman-distance triathlon. PLoS ONE 2017, 12, e0179324. [CrossRef]

60. Požgain, I.; Požgain, Z.; Degmečić, D. Placebo and Nocebo Effect: A Mini-Review; Medicinska naklada: Zagreb, Croatia, 2014; Volume 26.

61. Greenham, G.; Buckley, J.D.; Garrett, J.; Eston, R.; Norton, K. Biomarkers of Physiological Responses to Periods of Intensified, NonResistance-Based Exercise Training in Well-Trained Male Athletes: A Systematic Review and Meta-Analysis; Springer International Publishing: Berlin/Heidelberg, Germany, 2018; Volume 48.

62. Grossmann, M.; Wittert, G.A. Dysregulation of the Hypothalamic-Pituitary-Testicular Axis due to Energy Deficit. J. Clin. Endocrinol. Metab. 2021, 106, e4861-e4871. [CrossRef]

63. Casto, K.V.; Edwards, D.A. Testosterone, cortisol, and human competition. Horm. Behav. 2016, 82, 21-37. [CrossRef]

64. Hotta, Y.; Kataoka, T.; Kimura, K. Testosterone Deficiency and Endothelial Dysfunction: Nitric Oxide, Asymmetric Dimethylarginine, and Endothelial Progenitor Cells. Sex. Med. Rev. 2019, 7, 661-668. [CrossRef]

65. Habib, S.; Moinuddin; Ali, A. Role of Nitric Oxide in Sports Nutrition, 2nd ed.; Elsevier Inc.: Amsterdam, The Netherlands, 2018.

66. Rammos, C. Potential of dietary nitrate in angiogenesis. World J. Cardiol. 2015, 7, 652. [CrossRef]

67. Huerta Ojeda, Á. Efecto de la suplementación de L-arginina y L-citrulina sobre el rendimiento físico: Una revisión sistemática. Nutr. Hosp. 2019, 36, 1389-1402.

68. Nyakayiru, J.; van Loon, L.J.C.; Verdijk, L.B. Could intramuscular storage of dietary nitrate contribute to its ergogenic effect? A mini-review. Free Radic. Biol. Med. 2020, 152, 295-300. [CrossRef]

69. Brownlee, K.K.; Moore, A.W.; Hackney, A.C. Relationship between circulating cortisol and testosterone: Influence of physical exercise. J. Sports Sci. Med. 2005, 4, 76-83. [CrossRef]

70. Markus, I.; Constantini, K.; Hoffman, J.R.; Bartolomei, S.; Gepner, Y. Exercise-induced muscle damage: Mechanism, assessment and nutritional factors to accelerate recovery. Eur. J. Appl. Physiol. 2021, 121, 969-992. [CrossRef]

71. Le Plénier, S.; Goron, A.; Sotiropoulos, A.; Archambault, E.; Guihenneuc, C.; Walrand, S.; Salles, J.; Jourdan, M.; Neveux, N.; Cynober, L.; et al. Citrulline directly modulates muscle protein synthesis via the PI3K/MAPK/4E-BP1 pathway in a malnourished state: Evidence from in vivo, ex vivo, and in vitro studies. Am. J. Physiol. Endocrinol. Metab. 2017, 312, E27-E36. [CrossRef]

72. Botchlett, R.; Lawler, J.M.; Wu, G. l-Arginine and l-Citrulline in Sports Nutrition and Health, 2nd ed.; Elsevier Inc.: Amsterdam, The Netherlands, 2018.

73. Wylie, L.J.; Park, J.W.; Vanhatalo, A.; Kadach, S.; Black, M.I.; Stoyanov, Z.; Schechter, A.N.; Jones, A.M.; Piknova, B. Human skeletal muscle nitrate store: Influence of dietary nitrate supplementation and exercise. J. Physiol. 2019, 597, 5565-5576. [CrossRef]

74. Daab, W.; Bouzid, M.A.; Lajri, M.; Bouchiba, M.; Saafi, M.A.; Rebai, H. Chronic BRroot Juice Supplementation Accelerates Recovery Kinetics following Simulated Match Play in Soccer Players. J. Am. Coll. Nutr. 2021, 40, 61-69. [CrossRef] 
75. Liao, Y.; Su, R.; Zhang, P.; Yuan, B.; Li, L. Cortisol inhibits mTOR signaling in avascular necrosis of the femoral head. J. Orthop. Surg. Res. 2017, 12, 1-7. [CrossRef]

76. Morley, J.E. The mTOR Conundrum: Essential for Muscle Function, but Dangerous for Survival. J. Am. Med. Dir. Assoc. 2016, 17, 963-966. [CrossRef]

77. Jones, R.D.; Jones, T.H.; Channer, K.S. The influence of testosterone upon vascular reactivity. Eur. J. Endocrinol. $2004,151,29-37$. [CrossRef] 